\title{
Influence Coefficients of Constructive Parameters of Meander Slow-Wave System with Additional Shields
}

\author{
Edvardas Metlevskis (Researcher, Vilnius Gediminas Technical University), \\ Romanas Martavičius (Professor, Vilnius Gediminas Technical University), \\ Andrius Katkevičius (Associate Professor, Vilnius Gediminas Technical University), \\ Darius Plonis (Associate Professor, Vilnius Gediminas Technical University)
}

\begin{abstract}
Constructions of meander slow-wave systems with additional shields grounded at different positions are presented. The construction of meander slow-wave systems with additional shields grounded at both edges is investigated in detail. The influence of the main constructive parameters on the electrical characteristics of meander slow-wave systems with additional shields grounded at both edges is evaluated. The main constructive parameters of the investigated system are: the length of the conductor, the width of meander conductor, the width of additional shield, and the width of the gap between adjacent meander conductors.

Sonnet ${ }^{\circledR}$ software package, which is based on the method of moments, has been used during the investigation. The results of the influence of constructive parameters to the phase delay time, input impedance, and the width of pass-band of the system are discussed.
\end{abstract}

Keywords - Delay lines; Meander structures; Microwave devices; Parametric synthesis.

\section{INTRODUCTION}

Modern microwave devices, including meander systems, are designed using computer-aided design systems in nowadays. Meander systems are widely used in the applications of wireless communication systems and antennas [1]-[3], biomedical field [4], [5], filter production [6]-[8], couplers and in-phase inverters [9], [10], slow-wave systems (SSs) [11]-[15], and traveling waves tubes [16]-[18].

A designer synthesizes an initial variant of the meander SS by applying his experience and synthesis techniques. The calculated characteristics of the meander SS are compared with technical requirements during the procedure of analysis. The parameters of the system are configured, and the procedure of analysis is repeated again if the comparison results are not satisfied. The last two procedures are referred to as the optimization of the meander SS [19].

The above-discussed automated design is called parame-tric synthesis [20]. The sensitivity of the changes in the parameters of the system must be analyzed before determining the changes in order to facilitate the process of synthesis, the analysis and optimization of the computer-aided design. Otherwise, the accuracy may be lost, and parametric synthesis will not benefit but will absorb the valuable study time.

Artificial neural networks are applied in such kind of tasks in recent years for the modelling of filters [21]-[23], antennas [24], [25], and for the analysis of signals [26], [27]. The use of neural networks can help to resolve the accuracy and timeconsumption problems.
In order to properly synthesize the construction of meander slow-wave system with desirable electrical characteristics, the influence of the main constructive parameters on its electrical characteristics of meander slow-wave system is investigated in this article.

\section{Model of MEANDER Slow-WAVE SySTEMS WITH ADDITIONAL SHIELDS}

The main electrical characteristics of the meander SS are as follows: the width $\Delta F$ of pass-band, phase delay time $t_{\mathrm{d}}$, and characteristic impedance $Z_{\mathrm{C}}$. In general, these characteristics (except $\Delta F$ ) are determined or calculated in low-frequency domain. The monograph [18] states that the characteristic impedance $Z_{C}$ and the input impedance $Z_{\mathrm{IN}}$ are the same in homogenous dielectric and differ very little in inhomogeneous dielectric of meander SS with additional shields; therefore, the term "input impedance $Z_{\mathrm{IN}}$ " will be used further in the text.

The main constructive parameters of meander SS with additional shields are (Fig. 1): the thickness $h$ and the relative permittivity $\varepsilon_{\mathrm{r}}$ of dielectric substrate, the length $2 A$ and the width $w_{1}$ of one meander conductor strip, the width $w_{2}$ of additional shield, and the width $s$ of gap between adjacent strips [28].

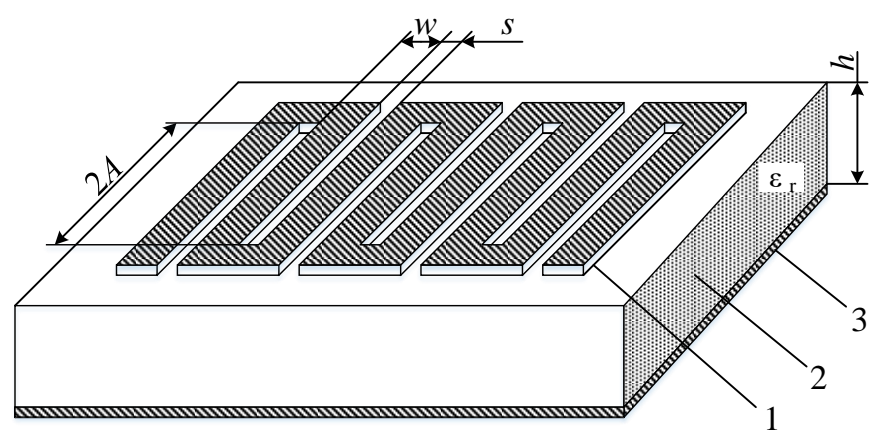

Fig. 1. Meander slow-wave system: $1-$ meander-shape conductor; 2 - dielectric substrate of relative permittivity $\varepsilon_{\mathrm{r}} ; 3$ - external shield [19].

The influence of constructive parameters is not the same to different electrical characteristics of the meander SS with additional shields. Therefore, in order to achieve optimal results of synthesis it is necessary to investigate the influence of the main constructive parameter to the electrical characteristics of the meander SSs with additional shields. The results of investigation will allow improving the algorithms of the parametric synthesis of such systems. The parametric synthesis of meander SSs with additional shields is a part of 
the process of computer-aided design during which constructive parameters are changed in order to get the desired electrical output characteristics of the system.

Four models of meander SSs with additional shields grounded at different positions are investigated (Fig. 2).

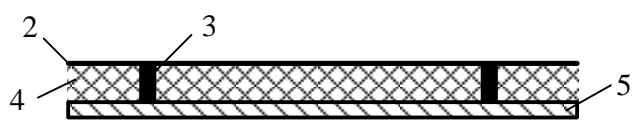

(a)

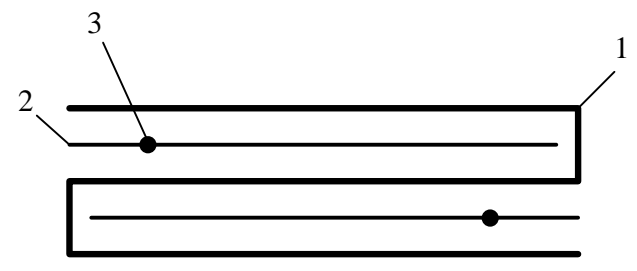

(b)

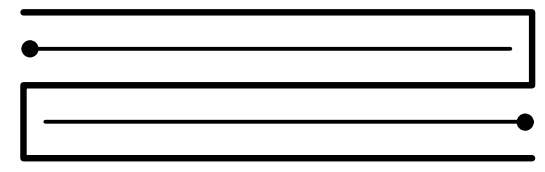

(c)

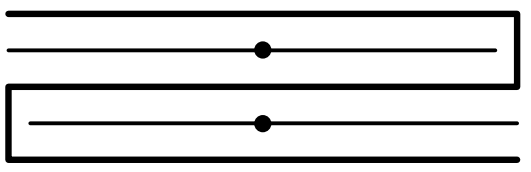

(d)

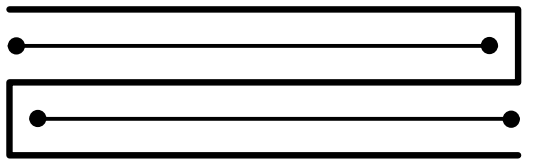

(e)

Fig. 2. (a) cross-section and the top views of meander slow-wave system when grounded via positioned at: (b) - the point between the edge and the center (like in cross-section view); (c) - one edge; (d) - center; (e) - both edges; 1 - meander-shape conductor; 2 - additional shield; 3 - grounded via; 4 - dielectric substrate; 5 - grounded external shield.

The model of meander SSs with additional shields grounded at both edges (Fig. 2e) is discussed in detail and is used in the numerical experiment.

The more detailed fragment of the topology of meander slow-wave systems with additional shields grounded at both edges is presented in Fig. 3. The initial dimensions of the analyzed system are: $2 A=20 \mathrm{~mm} ; w_{1}=0.5 \mathrm{~mm} ; w_{2}=0.25 \mathrm{~mm}$; $s=0.65 \mathrm{~mm} ; \varepsilon_{\mathrm{r}}=7.3$; and $h=0.5 \mathrm{~mm}$.

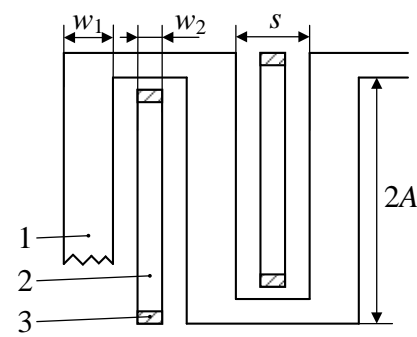

Fig. 3. The fragment of the topology of meander slow-wave system with additional shields grounded at both edges, where $2 A=20 \mathrm{~mm} ; w_{1}=0.5 \mathrm{~mm}$; $w_{2}=0.25 \mathrm{~mm} ; s=0.65 \mathrm{~mm} ; \varepsilon_{\mathrm{r}}=7.3 ; h=0.5 \mathrm{~mm}$.

The evaluation of the influence of constructive parameters to delay time, input impedance and the width of the pass-band of meander slow-wave systems with additional shields is possible with determination of impact coefficients. The influence of the particular constructive parameter can be represented by formula

$$
S=\left(\Delta p / p_{0}\right) /(\Delta d / d),
$$

where

$\Delta p$ - the variation of the electrical characteristic of meander slow-wave system;

$p_{0}$ - the value of the electrical characteristic of meander slow-wave system with initial constructive parameters;

$\Delta d$ - the change of selected constructive parameter;

$d$ - the initial value of the constructive parameter or meander slow-wave system with additional shields grounded at both edges.

Constructive parameters were reduced by $1 \%$ during the investigation and the determination of impact coefficients. For example, the change in phase delay time, which results from the reduction in the length $2 A$ of the strip of the meander conductor from $20 \mathrm{~mm}$ to $19.8 \mathrm{~mm}$, is shown in Fig. 4 .

The value of the phase delay time decreases when the length $2 A$ of the strip is reduced by $1 \%$ (Fig. 4). Therefore, it is possible to calculate the impact coefficient of the constructive parameter $2 A$ using the expression (1) after setting a change $\Delta t_{\mathrm{d}}$ of the phase delay time in the lower frequencies.

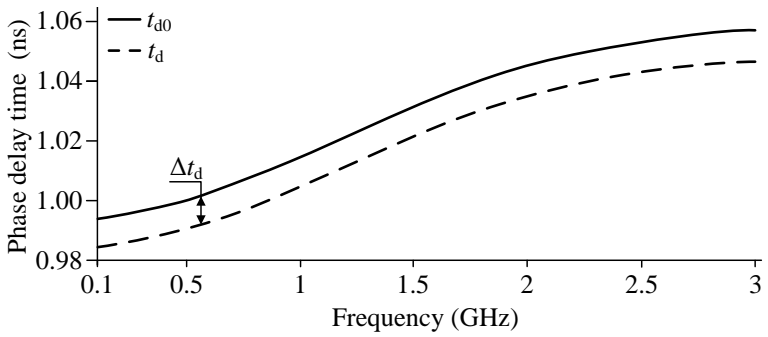

Fig. 4. Change in phase delay time when the length of a meander conductor is changed by one percent.

The calculation of the impact coefficients of the constructive parameters of meander slow-wave systems with additional shields grounded at both edges is provided in the next sections. 
As well as the sensitivity of the phase delay time, the input impedance and the width of pass-band are evaluated to the changes in constructive parameters. Sonnet ${ }^{\circledR}$ software package, which is based on the method of moments, has been used during the investigation [29].

\section{INFLUENCE OF CONSTRUCTIVE PARAMETERS TO THE PHASE DELAY TIME OF THE SYSTEM}

The results of the sensitivity investigation of phase delay time because of the changes in the length $2 A$ or the width $w_{1}$ of the conductor of meander slow-wave system with additional shields grounded at both edges are presented in Fig. 5.

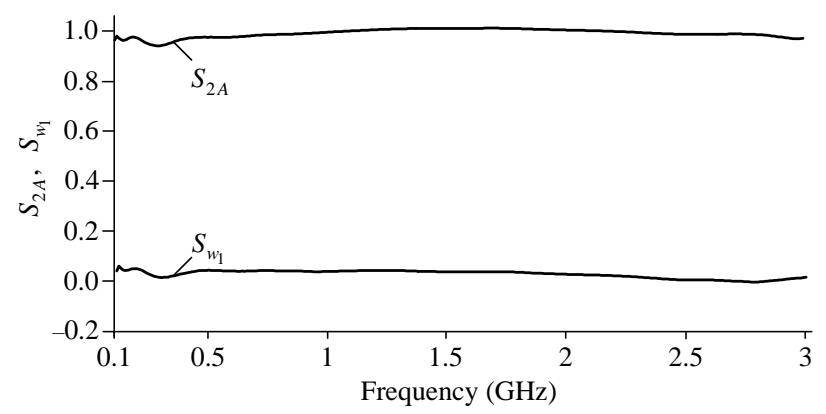

Fig. 5. Impact coefficients on the phase delay time of a system when changing: the length $2 A$ of meander conductor, and the width $w_{1}$ of meander conductor.

The values of impact coefficients versus frequency are presented when the length $2 A$ and the width $w_{1}$ of a conductor are reduced by $1 \%$. The curves, which are presented in the graphs, show that the value of the phase delay time of the meander SS with additional shields grounded at both edges reduces by about $1 \%$ when the conductor length $2 A$ reduces by $1 \%$. Changing the width of the meander conductor has a much lower impact on the phase delay time of the system. The value of the phase delay time reduces just by $0.06 \%$ when the width $w_{1}$ is reduced by $1 \%$ in this case.

The values of impact coefficients versus frequency are presented in Fig. 6 when the width $s$ of the gap between adjacent meander conductor strips is reduced by $1 \%$ (Fig. 6a), the width $w_{2}$ of the additional shields of the meander slowwave system with additional shields grounded at both edges is reduced by $1 \%$ (Fig. 6b).

The value of phase delay time decreases by $0.07 \%$ in the lower frequencies when the width of the gap between adjacent meander strips is reduced by $1 \%$. Meanwhile, the change in the width $w_{2}$ of additional shield has almost no impact on the phase delay time. The value of the impact coefficient is close to zero in lower frequencies in this case.

The results of the sensitivity investigation of phase delay time because of the changing parameters of the dielectric substrate of meander slow-wave system with additional shields are presented in Fig. 7. The impact coefficients of relative permittivity $\varepsilon_{\mathrm{r}}$ (Fig. 7a) and the thickness $h$ of the dielectric substrate (Fig. 7b) are presented in Fig. 7.

It is clear from the graphs that changing the relative permittivity $\varepsilon_{\mathrm{r}}$ has a greater influence on the phase delay time. The phase delay time is reduced by about $0.5 \%$ when $\varepsilon_{\mathrm{r}}$ is reduced by $1 \%$. Meanwhile, the impact coefficient of the thickness $h$ of dielectric substrate is negative. This means that the value of the phase delay time is increased by approximately $0.1 \%$ when the thickness $h$ is reduced by $1 \%$.

Summarizing the results it can be stated that the change in the length $2 A$ of the conductor has the greatest impact on the phase delay time of the meander slow-wave system with additional shields earthed at both edges. A smaller impact is observed when changing the relative permittivity $\varepsilon_{\mathrm{r}}$ and the thickness $h$ of dielectric substrate.

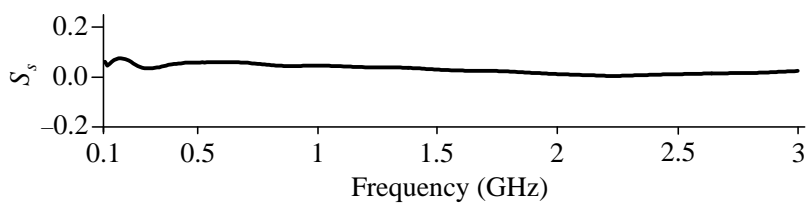

(a)

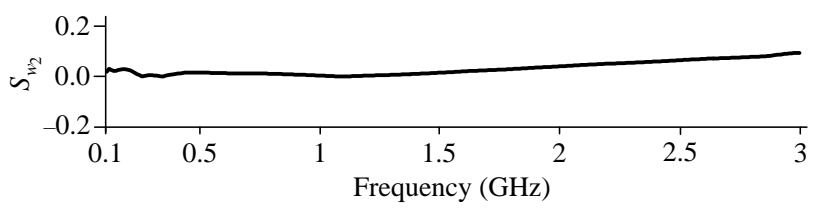

(b)

Fig. 6. Impact coefficients on the phase delay time of a system when changing: (a) the gap $s$ between adjacent meander conductors; (b) the width $w_{2}$ of additional shield.

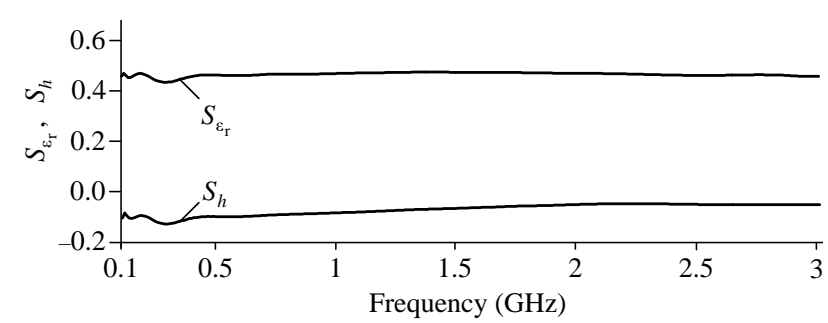

Fig. 7. Impact coefficients on the phase delay time of a system when changing: (a) the relative permittivity $\varepsilon_{\mathrm{r}}$; (b) the height $h$ of a dielectric substrate.

Meanwhile, the variation of the width $w_{1}$ of meander conductor, the width $w_{2}$ of additional shield, and the width $s$ of the gap between adjacent meander conductors almost do not change the phase delay time. The length $2 A$ of the meander conductor or the number of conductors, as well as the material of dielectric substrate must be changed in order to change the phase delay time.

\section{INFLUENCE OF CONSTRUCTIVE PARAMETERS TO THE INPUT IMPEDANCE OF THE SYSTEM}

The investigation results of the sensitivity of input impedance to the changes in length $2 A$ and the width $w_{1}$ of the conductor of meander slow-wave system with additional shields grounded at both edges are presented in Fig. 8. The values of impact coefficients versus frequency are shown when the length $2 A$ (Fig. 8a) or the width $w_{1}$ (Fig. 8b) of the conductor are reduced by $1 \%$.

Impact coefficient is close to zero and the input impedance value is almost unchanged when the length $2 A$ of the conductor is reduced by $1 \%$ (Fig. 8 , a). Changing the width of 
the meander conductor has a greater impact on the input impedance of the system.

The value of the input impedance is reduced by $0.3 \%$ in the lower frequencies when the width $w_{1}$ is reduced by $1 \%$. It is also appropriate that curves fluctuations occur in the higher frequencies. Curves fluctuations are caused by the incompatibility of the input impedance with the load resistance of the generator when the frequency increases.

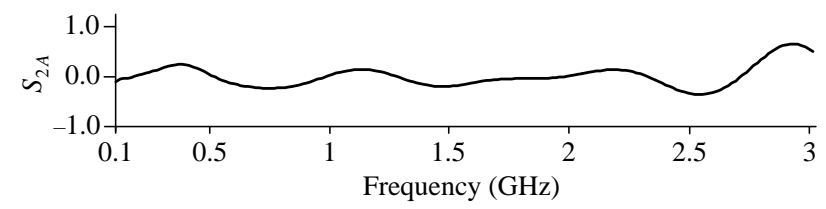

(a)

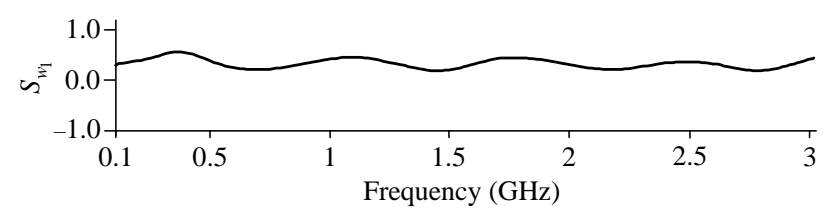

(b)

Fig. 8. Impact coefficients on the input impedance of a system when changing: (a) the length $2 A$ of meander conductor; (b) the width $w_{1}$ of meander conductor.

The values of impact coefficients versus frequency are presented in Fig. 9 when the width $s$ of the gap between adjacent meander conductors (Fig. 9a) and the width $w_{2}$ of additional shields of the meander slow-wave system with additional shields earthed at both edges (Fig. 9b) are reduced by $1 \%$.

The value of the input impedance is reduced by about $0.5 \%$ in the lower frequencies when the width of the gap between adjacent meander conductors is reduced by $1 \%$. Meanwhile, changing the width $w_{2}$ of additional shield has a greater impact on the input impedance of the meander slow-wave system with additional shields earthed at both edges. The value of impact coefficient is close to one in the lower frequencies in this case; therefore, the input impedance of the system is reduced by about $1 \%$ as well when $w_{2}$ is reduced by $1 \%$.

The investigation results of the sensitivity of the input impedance of the meander slow-wave system with additional shields earthed at both edges are presented in Fig. 9 when the parameters of dielectric substrate vary.

The impact coefficient of relative permittivity $\varepsilon_{\mathrm{r}}$ is presented in Fig. 10a, and the impact coefficient of the thickness $h$ of the dielectric substrate of the meander SS with additional shields earthed at both edges is presented in Fig. 10b.

Changing the relative permittivity has a greater impact on the input impedance of the system (Fig. 10). The impact coefficient $S$ acquires a negative value and the input impedance of the system increases by $0.5 \%$ when $\varepsilon_{\mathrm{r}}$ reduces by $1 \%$. Meanwhile, the impact coefficient of the thickness $h$ of the dielectric substrate is positive. This means that the value of the input impedance of the system is reduced by $0.2 \%$ when thickness $h$ is reduced by $1 \%$.

Summarizing the results it can be stated that the change in the width $w_{2}$ of additional shield has the greatest impact on the input impedance $Z_{\mathrm{IN}}$ of the meander slow-wave system with additional shields earthed at both edges. A smaller impact is observed when changing the width $s$ of the gap between adjacent meander conductors and the relative permittivity $\varepsilon_{\mathrm{r}}$ of dielectric substrate. The impact coefficients are even smaller and hardly reach $0.2-0.3$ of other constructive parameters such as thickness $h$ of the dielectric substrate and the width $w_{1}$ of meander conductors. Meanwhile, the variation of the length $2 A$ of meander conductor does not change the input impedance $Z_{\text {IN }}$ in the low frequencies. In addition, it should be noted that fluctuations are noticeable in the impact coefficients curves of input impedance during the variations of frequency.

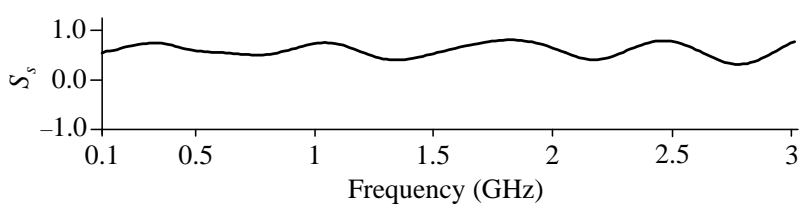

(a)

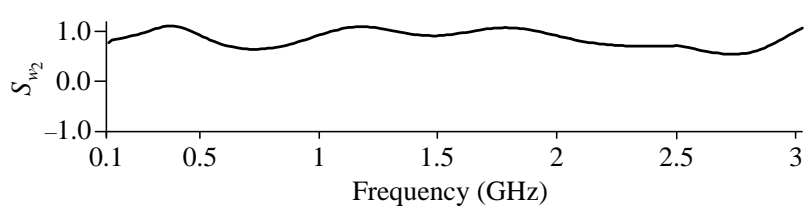

(b)

Fig. 9. Impact coefficients on the input impedance of a system when changing: (a) the gap $s$ between adjacent meander conductors; (b) the width $w_{2}$ of additional shield

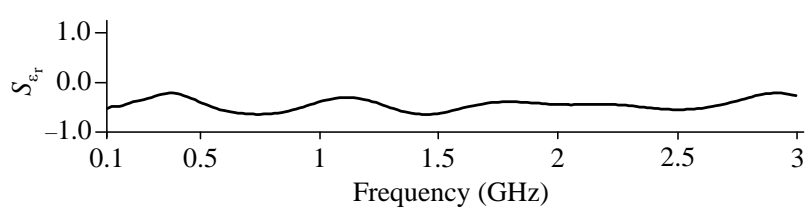

(a)

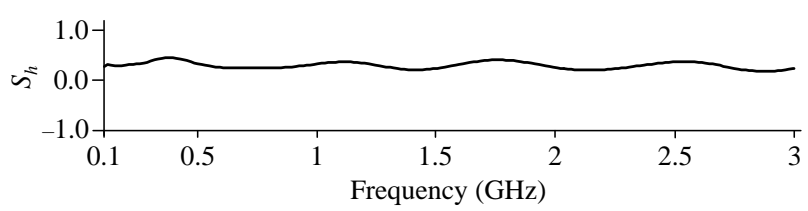

(b)

Fig. 10. Impact coefficients on the input impedance of a system when changing: (a) the relative permittivity $\varepsilon_{\mathrm{r}}$; (b) the height $h$ of a dielectric substrate.

Fluctuations occur due to the edges of the system, in which the size of the input impedance changes, and, therefore, inconsistency of signals tract arises.

\section{INFLUENCE OF CONSTRUCTIVE PARAMETERS TO THE WIDTH OF THE PASS-BAND}

The survey results of the impact coefficients of constructive parameters to the phase delay time and the input impedance of meander slow-wave system with additional shields earthed at both edges are summarized in Table I.

The sensitivity of the width of pass-band depending on the change in constructive parameters expressed through the influence coefficients is also shown in Table I. 
TABLE I

INFLUENCE OF THE CONSTRUCTIVE PARAMETERS OF MEANDER SLOW-WAVE SYSTEM WITH ADDITIONAL SHIELDS GROUNDED AT BOTH EDGES ON ITS ELECTRICAL PARAMETERS

\begin{tabular}{|c|c|c|c|}
\hline \multicolumn{2}{|l|}{$\begin{array}{l}\text { Parameters of structure and } \\
\text { topology }\end{array}$} & \multicolumn{3}{|c|}{$\begin{array}{l}\text { Impact coefficients when appropriate } \\
\text { construction parameter decreases by } 1 \%\end{array}$} \\
\hline Length $2 A$ of meander conductor & 0 & 1 & -1.36 \\
\hline Width $w_{1}$ of meander conductor & 0.3 & 0.06 & -0.68 \\
\hline Width $w_{2}$ of additional shield & 1 & 0 & 0 \\
\hline $\begin{array}{c}\text { Width } s \text { of the gap between } \\
\text { adjacent meander conductor }\end{array}$ & 0.5 & 0.07 & -0.68 \\
\hline $\begin{array}{c}\text { Relative permittivity } \varepsilon_{\mathrm{r}} \text { of } \\
\text { dielectric substrate }\end{array}$ & -0.5 & 0.5 & -1.36 \\
\hline $\begin{array}{c}\text { Thickness } h \text { of dielectric } \\
\text { substrate }\end{array}$ & 0.2 & -0.1 & -0.68 \\
\hline
\end{tabular}

Changes in the length $2 A$ of meander conductor and the dielectric permittivity $\varepsilon_{\mathrm{r}}$ of substrate have the greatest impact on the width of the pass-band (Table I.). The width $\Delta F$ of the pass-band increases by about $1.36 \%$ when these parameters are reduced by $1 \%$. Changes in the width $w_{1}$ of meander conductors, the width $s$ of the gap between adjacent meander conductors and the thickness $h$ of dielectric substrate have a significant impact on the width of the pass-band. The width $\Delta F$ of the pass-band increases by $0.68 \%$ when these parameters are reduced by $1 \%$. Changing the width $w_{2}$ of additional shield does not affect the width of the pass-band.

\section{CONCLUSION}

In summary it can be concluded that a certain electrical parameter of meander slow-wave systems with additional shields earthed at both edges depends on several constructive parameters. For example, the required values of the input impedance $Z_{\mathrm{IN}}$ can be obtained by changing the width $s$ of the gap between adjacent conductors, the relative permittivity $\varepsilon_{\mathrm{r}}$ of substrate, or the width $w_{1}$ of meander conductor. The required value of the delay time can be obtained by changing the length $2 A$ of the meander conductor or the parameters $\varepsilon_{\mathrm{r}}$ and $h$ of the dielectric substrate.

However, not all of the above-mentioned parameters are changeable. Some constructive parameters could not be varied freely since the chosen technology of production limits their variation. These parameters are the thickness $h$ and the relative permittivity $\varepsilon_{\mathrm{r}}$ of the dielectric substrate. The number of constructive parameters that can vary decline, and the process of synthesis becomes simpler in that case. Therefore, the basic parameters that vary during synthesis are the length $2 A$ and the width $w_{1}$ of meander conductor, the width $w_{2}$ of additional shield, and the width $s$ of the gap between adjacent strips of meander.

The algorithm of the synthesis of meander slow-wave systems with additional shields earthed at both edges can be realized when the influence of the constructive parameters to electrical characteristics is known.

\section{REFERENCES}

[1] C. Chua and S. Aditya, "A 3-D U-Shaped Meander-Line Slow-Wave Structure for Traveling-Wave-Tube Applications," in IEEE Trans. on Electron Devices, vol. 60, no. 3, pp. 1251-1256, March, 2013. https://doi.org/10.1109/TED.2013.2241438

[2] P. Vikram, H. V. Kumaraswamy and R. K. Manjunath, "Design and Simulation of Meander Line Antenna for RFID Passive Tag," Int. J. of Advanced Research in Computer and Commun. Eng., vol. 4, pp. 119$122,2015$.

[3] A. Kosi and M. Solar, "Solutions for Improving Reliabilities of DVB$\mathrm{T} / \mathrm{H}$ Transmitters, Systems and Networks," J. of Scientific \& Ind. research, vol. 69, pp. 580-585, 2010.

[4] N. M. Faudzi, M. T. Ali, I. Ismail, N. Ya'acob, H. Jumaat and N. H. M. Sukaimi, "UHF-RFID Tag Antenna with Miniaturization Techniques", in 2013 10th Int. Conf. on Elect. Eng./Electron., Comput., Telecommun. and Inform. Technology, Krabi, 2013, pp. 1-5. https://doi.org/10.1109/ecticon.2013.6559513

[5] R. Brinda and S. S. Preethy, "Miniaturized Antenna with Combination of Meander and Square Spiral Slots for Biomedical Applications," Int. J. of Comput. Applicat., vol. 85, no. 4, pp. 21-24, 2014. https://doi.org/10.5120/14829-3074

[6] S. Lin, H. Cui, L. Wu, W. Wang and X. Sun, "Design of BroadsideCoupled Parallel Line Millimetre-Wave Filters by Standard $0.18-\mu \mathrm{m}$ Complimentary Metal Oxide Semiconductor Technology," IET Microwaves, Antennas \& Propagation, vol. 6, no. 1, pp. 72-78, 2012. http://dx.doi.org/10.1049/iet-map.2011.0024

[7] K. W. Hsu and W. H. Tu, "Sharp Rejection Quad-Band Bandpass Filter Using Meandering Structure," Electronics Letters, vol. 48, no. 15, pp. 935-937, 2012. https://doi.org/10.1049/el.2012.1735

[8] D. Cui, Y. Liu, Y. Wu, S. Li and C. Yu, "A Compact Bandstop Filter Based On Two Meandered Parallel-Coupled Lines," Progress In Electromagnetics Research. pp. 271-279, 2011. https://doi.org/10.2528/PIER11061902

[9] P. Deo, D. Mirshekar-Syahkal, L. Seddon, S. E. Day and F. Anibal Fernandez, "Liquid Crystal Based Patch Antenna Array for $60 \mathrm{GHz}$ Applications", in 2013 IEEE Radio and Wireless Symposium, Austin, TX, pp. 127-129, 2013. https://doi.org/10.1109/rws.2013.6486663

[10] J. Wu, J. Lou, M. Li, G. Yang, X. Yang, J. Adams, and N. X. Sun, "Compact, Low-Loss, Wideband, and High-Power Handling Phase Shifters with Piezoelectric Transducer-Controlled Metallic Pertruber," IEEE Trans. on Microwave Theory and Techniques, vol. 60, no. 6, pp. 1587-1594, 2012. https://doi.org/10.1109/TMTT.2012.2189240

[11] L. Hansuek, C. Tong, L. Jiang and K. Vahala, "Ultra-Low-Loss Delay Lines and Resonators on a Silicon Chip", in IEEE Photonics Conf. 2012, Burlingame, CA, pp. 518-519, 2012. https://doi.org/10.1109/ipcon.2012.6358721

[12] A. Gurskas, V. Urbanavicius and R. Martavicius, "Evaluation of the Microstrip Lines Connectors in the Meander Delay Line Model," Electron. and Elect. Eng., vol. 99, no. 3, pp. 39-42, 2010.

[13] L. Liu, Y. Wei, J. Xu, Z. Lu, H. Yin, L. Yue, H. Gong, G. Zhao, Z. Duan, W. Wang and Y. Gong, "A Novel Slotted Helix Slow-Wave Structure for Millimeter-Wave Traveling-Wave Tube," Progress in Electromagnetics Research, vol. 135, pp. 347-362, 2013. https://doi.org/10.2528/PIER12112611

[14] A. Krukonis, S. Mikucionis and V. Urbanavicius, "The Influence of Non-Uniformity of the Multi-Conductor Line Parameters on Frequency Responses of the Meander Delay Line," Electron. and Elect. Eng., vol. 19 , no. 6 , pp. $81-86,2013$. https://doi.org/10.5755/j01.eee.19.6.4279

[15] C. Chen, "Effect of Structural Parameters on High Frequency Characteristics of Microstrip Meander-Line Slow-Wave Structure," Appl. Mechanics and Materials, vol. 241-244, pp. 698-702, Dec. 2012. https://doi.org/10.4028/www.scientific.net/AMM.241-244.698

[16] M. Sumathy, S. K. Datta and L. Kumar, "Folded Meander-Line SlowWave Structure for Millimeter-Wave TWTs", in IEEE 14th International Vacuum Electronics Conference (IVEC), Paris, France, 2013, pp. 1-2. https://doi.org/10.1109/ivec.2013.6571176

[17] N. Bai, N. China, M. Shen and X. Su, "Investigation of Microstrip Meander-Line Traveling-Wave Tube Using EBG Ground Plane," IEEE Trans. of Electron Devices, vol. 62, no. 5, pp. 1622-1627, 2015. https://doi.org/10.1109/TED.2015.2411314 
[18] M. Boyle, M. Barsanti and R. True, "Magnetic Interaction Between Traveling Wave Tubes and Its Effect on Performance and Reliability," in 2012 IEEE Thirteenth Int. Vacuum Electron. Conf. (IVEC), Monterey, CA, 2012, pp. 155-156. https://doi.org/10.1109/ivec.2012.6262114

[19] S. Štaras, R. Martavičius, J. Skudutis, V. Urbanavičius and V. Daškevičius, Wide-band slow-wave systems: simulation and application, New York, NY: CRC Press, Taylor \& Francis Group, 2012, $460 \mathrm{p}$.

[20] S. Štaras, R. Martavičius, J. Skudutis, V. Urbanavičius and V. Daškevičius, Plačiajuosčiu lètinimo ịtaisu modeliavimas ir taikymas, Vilnius: Technika, 2010, 442 p. https://doi.org/10.3846/1766-M

[21] M. Yahia, J. W. Tao, H. Benzina and M. N. Abdelkrim, "Ridged Waveguide Filter Optimization Using the Neural Networks and A Modified Simplex Method," Int. J. of Innovation, Management and Technology, vol. 1, no. 3, pp. 259-263, 2010.

[22] G. S. Tomar, V. S. Kushwah and S. Saxena, "Design of Microstrip Filters Using Neural Network," in Second Int. Conf. on Commun. Software and Networks, vol. 1, no. 1, Singapore, 2010, pp. 568-572. https://doi.org/10.1109/iccsn.2010.103

[23] J. J. Michalski, "Artificial Neural Networks Approach in Microwave Filter Tuning," Progress in Electromagnetics Research, vol. 13, pp. 173-188, 2010. https://doi.org/10.2528/PIERM10053105

[24] J. Singh, A. P. Singh, T. S. Kamal, "Design of Circular Microstrip Antenna Using Artificial Neural Networks," in Proc. of the World Congr. on Eng., vol. 2, no. 1, London, 2011, pp. 9-12.

[25] T. B. Roy, J. Sah, M. Datta and U. Borah, "Modelling of Aperture Coupled Microstrip Antenna Using Different Artificial Neural Network Techniques," Int. J. of Advanced Research in Computer and Commun. Eng., vol. 4, no. 1, pp. 309-402, 2015. https://doi.org/10.17148/IJARCCE.2015.4187

[26] L. Stašionis and A. Serackis, "Experimental Study of Spectrum Sensing Algorithm with Low Cost SDR," in XXII-nd Int. Conf. on Electromagnetic Disturbances, Vilnius, 2012, pp. 117-120.

[27] L. Stašionis and A. Serackis, "Burst Signal Detector Based on Signal Energy and Standard Deviation," Elektronika ir Elektrotechnika, vol. 20 no. 2 , pp. $48-51,2014$. https://doi.org/10.5755/j01.eee.20.2.6384

[28] E. Metlevskis and R. Martavičius, "Frequency Characteristics of the Input Impedance of Meander Slow-wave System with Additional Shields," Electronics and Elect. Eng., vol. 20, no. 4, pp. 59-62, 2014. https://doi.org/10.5755/j01.eee.20.3.6678

[29] J. Ureel, and D. De Zutter, "Shape Sensitivities of Capacitances of Planar Conducting Surfaces Using the Method of Moments," IEEE Trans. on Microwave Theory and Techniques, vol. 44, no. 2, pp. 198 207, 1996. https://doi.org/10.1109/22.481568

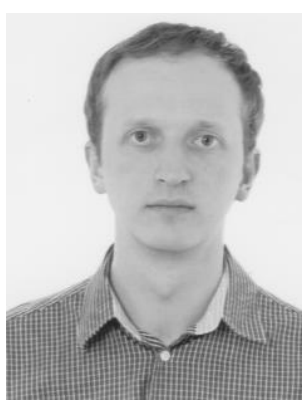

Edvardas Metlevskis received the B.Sc. and M.Sc. in informatics engineering and the Ph.D. degree in electrical and electronic engineering from Vilnius Gediminas Technical University in 2008, 2010, and 2014, respectively.

$\mathrm{He}$ is a researcher at the Department of Electronic system of the Vilnius Gediminas Technical University. His main research interests include electromagnetic field theory, super high frequency technologies and microwave devices, signal processing, and embedded systems.

Address: Vilnius Gediminas Technical University, Faculty of Electronics, Naugarduko str. 41-427, Vilnius, LT-03227, Lithuania.

E-mail: edvardas.metlevskis@gmail.com

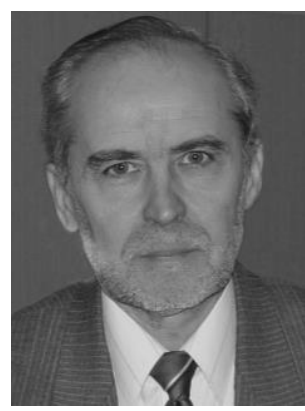

Romanas Martavičius received his scientific degrees in electrical and electronic engineering: the B.Sc. degree from Vilnius Filial of Kaunas Polytechnic Institute in 1968, the Ph.D. degree from Kaunas Polytechnic Institute in 1993, and the habilitation degree from Vilnius Gediminas Technical University in 1997.

$\mathrm{He}$ is a Habilitated Professor at the Department of Electronic system at the Vilnius Gediminas Technical University. His main research interests include electromagnetic field theory, super-high frequency technologies, microwave devices, and signal processing.

R. Martavičius is a member of the IEEE, and an active member of the IEEE Microwave Theory and Techniques.

Address: Vilnius Gediminas Technical University, Faculty of Electronics, Naugarduko str. 41-427, Vilnius, LT-03227, Lithuania.

E-mail: romanas.martavicius@vgtu.lt

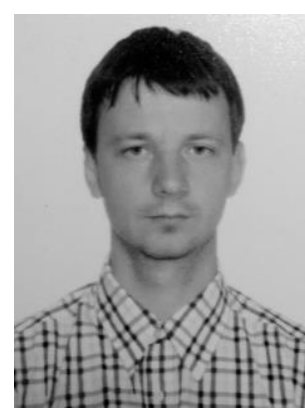

Andrius Katkevičius received the B.Sc., M.Sc. and Ph.D. degree in electrical and electronic engineering from Vilnius Gediminas Technical University in 2007, 2009, and 2013, respectively.

$\mathrm{He}$ is an Associate Professor at the Department of Electronic system of the Vilnius Gediminas Technical University. His main research interests include electromagnetic field theory, super-high frequency technologies and microwave devices, signal processing, multimedia and embedded systems.

A. Katkevičius is a member of the IEEE, and an active member of the IEEE Microwave Theory and Techniques.

Address: Vilnius Gediminas Technical University, Faculty of Electronics, Naugarduko str. 41-415, Vilnius, LT-03227, Lithuania.

E-mail: andrius.katkevicius@vgtu.lt

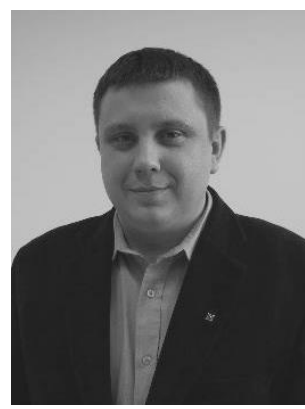

Darius Plonis received the B.Sc., M.Sc. and Ph.D. degree in electrical and electronic engineering from Vilnius Gediminas Technical University in 2008, 2010, and 2014, respectively.

$\mathrm{He}$ is an Associate Professor at the Department of Electronic system of the Vilnius Gediminas Technical University. His main research interests include electromagnetic field theory, super-high frequency technologies and microwave devices, signal processing, multimedia and embedded systems.

D. Plonis is a member of the IEEE, an active member of the IEEE Microwave Theory and Techniques, and currently serves as the Officer of the Membership Development/Student Activities of the IEEE Lithuania Section.

Address: Vilnius Gediminas Technical University, Faculty of Electronics, Naugarduko str. 41-413, Vilnius, LT-03227, Lithuania.

E-mail: darius.plonis@vgtu.lt 